\title{
Concentration of selected transition metals in layer hens non-infested and infested with Dermanyssus gallinae
}

\author{
Anna Spodniewska ${ }^{1}$, Dariusz Barski ${ }^{1}$, Rajmund Sokół ${ }^{2}$ \\ ${ }^{1}$ University of Warmia and Mazury in Olsztyn, Faculty of Veterinary Medicine, Department of Pharmacology \\ and Toxicology, Olsztyn, Poland \\ ${ }^{2}$ University of Warmia and Mazury in Olsztyn, Faculty of Veterinary Medicine, Department of Parasitology \\ and Invasive Diseases, Olsztyn, Poland \\ Received December 22, 2011 \\ Accepted May 16, 2012
}

\begin{abstract}
The aim of this study was to determine the concentration of selected transition metals, i.e. iron $(\mathrm{Fe})$, copper $(\mathrm{Cu})$ and zinc $(\mathrm{Zn})$ in the livers of laying hens free from and infested with the red mite (Dermanyssus gallinae) and to explain the effects of the invasion of this parasite on the content of those elements. The study was carried out on $24 \mathrm{Hy}$-Line Brown hens bred in battery cages. The birds were divided into two groups, free from and infested with D. gallinae. Concentration of analysed metals was determined using atomic absorption spectrophotometry. Based on this experiment, it was proved that a long-term (52 weeks) exposure of hens to $D$. gallinae resulted in a significant $(P<0.05)$ decrease of $\mathrm{Fe}, \mathrm{Cu}$ and $\mathrm{Zn}$ in the liver. The mean content of analysed metals in the group infested with the parasite amounted to $31.42 \mathrm{mg} \mathrm{Fe} /$ $\mathrm{kg}, 2.71 \mathrm{mg} \mathrm{Cu} / \mathrm{kg}$ and $22.64 \mathrm{mg} / \mathrm{kg}$, whereas in the non-infested group it was $38.51 \mathrm{mg} \mathrm{Fe} / \mathrm{kg}$, $3.12 \mathrm{mg} \mathrm{Cu} / \mathrm{kg}$ and $26.53 \mathrm{mg} \mathrm{Zn} / \mathrm{kg}$. No significant $(P<0.05)$ alterations in haematological indicators were found between the examined groups of birds. The results may suggest that 3 weeks of recovery in hens are sufficient to bring about a considerable increase in concentration of analysed transition metals in the liver.
\end{abstract}

Copper, zinc, iron, birds, red mite

The red mite (Dermanyssus gallinae) is the most harmful ectoparasite of poultry. It attacks both domestic and wild birds at any age and may occur in poultry units using different rearing and breeding systems (Guy et al. 2004). Infection with this parasite leads to severe irritation of birds, blood loss as a result of mite preying, toxic and allergenic effects of the parasite's saliva, mechanical damage to body integuments and increased susceptibility of birds to pathogenic micro-organisms.

Metals, including transition metals such as iron, copper and zinc play an important role in living organisms. They are components and co-factors of numerous enzymes and proteins necessary to ensure proper body functions. Iron is the best-known, and with regard to its ability to rapid acceptance and transmission of electrons, the most dangerous of the transition metals. It participates in many metabolic processes, DNA synthesis, respiratory chain and processes leading to cell damage as a result of oxidative stress (Emerit et al. 2001). Copper is a natural component of many constitutional proteins of enzymatic properties (e.g., ceruloplasmin, cytochrome oxidase, metallothionein, superoxide dismutase) and it participates in numerous processes catalysing oxidation/ reduction reactions (Gaetke and Chow 2009). It demonstrates a haematopoetic effect, modulates immune processes and is necessary for the proper activity of many vitamins and hormones. Zinc fulfils a multidirectional biological function in the body, acting through numerous metalloenzymes and hormones, of which it is a component or an activator. It is also considered an essential element for the immune response, since 
$\mathrm{Zn}$ affects and cooperates in a specific way with various components of the immune system (Hirano et al. 2008).

Because of their content of unpaired electrons, ions of transition metals, participate in free radical reactions as a substrate for formation of highly reactive radicals. An increased content of reactive oxygen species and effeteness of defence mechanisms leads to cell dysfunction and incidence of various diseases (Lykkesfeld and Svendsen 2007).

The available literature provides only a limited number of studies examining the effects of D. gallinae on the content of substances essential for the organism, including the elements. However, a definite majority of them concern changes in homeostasis under the influence of the oxidative stress arising as a result of various parasite invasions (Georgieva et al. 2006; Camkerten et al. 2009).

In view of the scarce reports concerning the influence of the red mite on the content of elements required by the organism, e.g. macro- and micro-elements, the aim of this study was to determine the concentration of selected transition metals, i.e. iron $(\mathrm{Fe})$, copper $(\mathrm{Cu})$ and zinc ( $\mathrm{Zn})$ in the livers of laying hens free from and infested with Dermanyssus gallinae and to explain the effects of the invasion of this parasite on the content of those elements.

\section{Materials and Methods}

The experiment was performed on 24 Hy-Line Brown layer hens raised in a battery cage system. Hens were taken from the henhouse populated by about 80,000 birds. The henhouse was naturally infested with Dermanyssus gallinae. Randomly selected hens 49-weeks old were divided into two groups of 12 birds. Both groups of birds were put in separate rooms, with six birds per cage; zoohygienic conditions were identical to those at the farm. Hens were fed with fodder originating from the home farm, provided water ad libitum and kept under the same light regime as at the farm.

The first group of birds consisted of hens sprayed twice with Butox 50 preparation manufactured by Hoechst, Germany (active substance - deltamethrin) at a dose of $1 \mathrm{ml} / 11 \mathrm{H}_{2} \mathrm{O}$. The first spraying took place directly on the farm, and the second spraying was applied after six days in the experimental room. This group was considered to be free from $D$. gallinae. The other group included birds infested with $D$. gallinae and was not treated. Invasion of the parasite in both groups was monitored until the end of the experiment, i.e. 3 weeks since the birds were taken in to the animal house).

In week 52 of life, all hens were weighed and their blood was taken from wing veins for haematological examinations; next all birds were slaughtered by fast decapitation and afterwards their livers were collected.

Using an ABX Vet device the concentration of haemoglobin (HGB) was marked in the whole blood. Upon diluting the whole blood with the Türk liquid, the number of white blood cells (WBC) was counted in a Thom chamber, and the number of red blood cells (RBC) was calculated upon diluting the whole blood with Hayem liquid in a Bürker chamber. The mean corpuscular haemoglobin (MCH), the mean corpuscular haemoglobin concentration (MCHC), and the mean corpuscular volume (MCV) was calculated according to the generally accepted standards.

Before performing analyses of metal concentration, the livers were frozen and stored at $-25{ }^{\circ} \mathrm{C}$. Quantitative determination of iron, copper and zinc concentration in the liver, after previous mineralization, was carried out using atomic absorption spectrophotometry, with a UNICAM 939 Solar spectrophotometer (Szkoda and Żmudzki 1990). Each measurement was performed three times, and the results obtained were the mean of those determinations.

The experiment was conducted according to the guidelines of the "Animal Protection Act" and recommendations of the Local Ethics Committee for Animal Experiments at the University of Warmia and Mazury in Olsztyn, Poland.

The data were statisticaly analysed to Student's $t$-test using the variance analysis. The level of $P<0.05$ was considered as significant.

\section{Results}

The natural invasion of $D$. gallinae before the beginning of the experiment (directly on the farm) was 300 red mite females in $100 \mathrm{~g}$ of the sediment sampled from the floor and from under the cages. After the end of the study, presence of parasites was not found in the non-infested group of hens, whereas in birds infested with red mites their number was 681.

The mean concentration of iron $(\mathrm{Fe})$, copper $(\mathrm{Cu})$ and zinc $(\mathrm{Zn})$ determined in the hen livers are presented in Table 1, showing arithmetic means, standard error of the mean (SEM), as well as the concentration range (min-max). The concentration of metals is presented in $\mathrm{mg} \cdot \mathrm{kg}^{-1}$ of fresh tissue. 
Table 1. Concentration of $\mathrm{Fe}, \mathrm{Cu}$ and $\mathrm{Zn}$ in the liver of layer hens non-infested and infested with Dermanyssus gallinae ( $\mathrm{mg} / \mathrm{kg}$ of fresh tissue)

\begin{tabular}{lcccc}
\hline Group of hens & & $\mathrm{Fe}(\mathrm{mg} / \mathrm{kg})$ & $\mathrm{Cu}(\mathrm{mg} / \mathrm{kg})$ & $\mathrm{Zn}(\mathrm{mg} / \mathrm{kg})$ \\
\hline Non-infested with & $\overline{\mathrm{x}} \pm \mathrm{SEM}$ & $38.51 \pm 2.44$ & $3.12 \pm 0.12$ & $26.53 \pm 0.82$ \\
Dermanyssus gallinae & min-max & $28.01-48.45$ & $2.65-3.56$ & $22.68-29.77$ \\
Infested with & $\overline{\mathrm{x}} \pm \mathrm{SEM}$ & $31.42^{*} \pm 2.36$ & $2.71^{*} \pm 0.13$ & $22.64^{*} \pm 1.01$ \\
Dermanysus gallinae & min-max & $21.38-39.30$ & $2.13-3.29$ & $18.54-29.03$ \\
\hline
\end{tabular}

Values expressed as means \pm SEM (standard error of the mean)

*significance $P<0.05$ to the group of hens non-infested with $D$. gallinae

Table 2. Average values of haematological indicators in layer hens non-infested and infested with Dermanyssus gallinae

\begin{tabular}{lcc}
\hline Analysed index & $\begin{array}{c}\text { Non-infested with } \\
\text { Dermanyssus gallinae }\end{array}$ & $\begin{array}{c}\text { Infested with } \\
\text { Dermanyssus gallinae }\end{array}$ \\
\hline RBC $\left(10^{12} / 1\right)$ & $2.88 \pm 0.14$ & $2.54 \pm 0.15$ \\
WBC $\left(10^{9} / 1\right)$ & $13.25 \pm 3.40$ & $15.09 \pm 3.81$ \\
HCT $(\%)$ & $31.0 \pm 1.2$ & $29.0 \pm 1.0$ \\
HGB $(\mathrm{g} / \mathrm{l})$ & $128.5 \pm 6.94$ & $118.2 \pm 5.11$ \\
MCH (pg) & $45.27 \pm 1.63$ & $45.89 \pm 0.99$ \\
MCHC (g/l) & $374.7 \pm 9.58$ & $358.4 \pm 11.64$ \\
MCV (fl) & $124.6 \pm 5.55$ & $118.36 \pm 4.87$ \\
\hline
\end{tabular}

RBC - red blood cells; WBC - white blood cells; HTC - haematocrit; HGB - haemoglobin; MCH - mean corpuscular haemoglobin; $\mathrm{MCHC}$ - mean corpuscular haemoglobin concentration; MCV - mean corpuscular volume Values expressed as means \pm SEM (standard error of the mean)

*significance $P<0.05$ to the group of hens non - infested with $D$. gallinae

Based on our experiment, it was demonstrated that long-term exposure of laying hens to $D$. gallinae invasion resulted in significant $(P<0.05)$ lowering of the content of all analysed metals compared to birds free from the parasite. The greatest decrease was found in the content of Fe. Its concentration in the group of hens infested with red mite amounted to $31.42 \mathrm{mg} \mathrm{Fe} / \mathrm{kg}$, whereas in birds non-infested with D. gallinae it was $38.51 \mathrm{mg} \mathrm{Fe} /$ $\mathrm{kg}$. A similar relation of lower intensity was observed in $\mathrm{Cu}$ and $\mathrm{Zn}$, where the mean concentration of these metals amounted to: $2.71 \mathrm{mg} \mathrm{Cu} / \mathrm{kg}$ and $3.12 \mathrm{mg} \mathrm{Cu} / \mathrm{kg}$, and 22.64 $\mathrm{mg} \mathrm{Zn} / \mathrm{kg}$ and $26.53 \mathrm{mg} \mathrm{Zn} / \mathrm{kg}$, respectively (Table 1).

No clinical symptoms of anaemia were observed in birds during the experiment. No significant alterations were found in haematological indicators between examined groups of hens (Table 2).

\section{Discussion}

Parasite invasions, including red mite (Dermanyssus gallinae), are a serious problem in poultry breeding (Arkle et al. 2004; Zenner et al. 2009). Mass and long-term invasion leads to bird anxiety, strong anaemia, as well as somatic stress (Kowalski and Sokół 2009). A non-specific response towards parasites can also be the generation of free radicals and the emergence of oxidative stress (Kolodziejczyk et al. 2006).

Disorders in the proper functioning of the organism as a consequence of many diseases and stress increase the demand for nutrients, including vitamins and mineral substances. Iron deficiency in the organism can originate from disorders concerning its absorption, 
transport, storage and cellular release. It was also proven that a reduced $\mathrm{Fe}$ content can be caused by anaemia ( $\mathrm{Lieu}$ et al. 2001). A decrease of Fe content in the liver of about $18.5 \%$ observed in the present study probably resulted from a loss of blood due to $D$. gallinae preying. Parasitic invasion may also possibly lead to disturbances of $\mathrm{Fe}$ absorption and its distribution in tissues. Concentrations of copper and iron in the body are closely interrelated, because $\mathrm{Cu}$ found in ceruloplasmin regulates the metabolism and $\mathrm{Fe}$ transport. The $13 \%$ decrease in the $\mathrm{Cu}$ content observed in our study in the liver of hens exposed to $D$. gallinae could therefore be due to a reduced content of Fe. Zinc deficiency arises in many both acute and chronic infectious diseases (bacterial, viral or parasitic) and inflammatory conditions of various origin (Stefanidou et al. 2006). Injuries, blood loss and surgery wounds also contribute to reduction of Zn content in blood (Stehbens 2003). Blood loss caused by D. gallinae in our studies could also probably be the cause of the decrease in $\mathrm{Zn}$ content in the bird liver. A lowered $\mathrm{Zn}$ content could also result from stress related to red mite parasitism, since the irritation of hens and skin lesions caused by the parasite can also contribute to the emergence of stress which, depending on the intensity, can bring about a deterioration of the general condition and the immunity of the organism (Kowalski et al. 2006). It is also confirmed by the increased number of WBC in blood of hens observed in our studies.

Transition metals, on the one hand, are considered to be elements largely contributing to the creation of free radicals, while on the other, due to their abilities to accept or to donate electrons, they reveal potential antioxidative properties (Evans and Hallivell 2001) and therefore can constitute an important element of many enzymes and proteins with antioxidative properties. Iron is one of the components of the heme system in the active centre of catalase (CAT), an enzyme which participates in antioxidative protection. Copper and zinc make up an integral part of superoxide dismutase ( $\mathrm{Cu}, \mathrm{Zn}-\mathrm{SOD})$, which plays a protective role against the effects of free radicals. The content of $\mathrm{Fe}, \mathrm{Cu}$ and $\mathrm{Zn}$ in the body determines the activity of those enzymes, and therefore the level of oxidative stress. In our previous research concerning the activity of antioxidative enzymes in laying hens exposed to invasion of $D$. gallinae, we found significant changes in the level of CAT, SOD and GPx activity (Sokół et al. 2008), which could be caused by a lower content of the analysed metals.

Research carried out in recent years demonstrates a relation between parasitic invasion and emergence of oxidative stress (Grewal et al. 2005). A decrease in $\mathrm{Cu}$ and $\mathrm{Zn}$ content in the liver was reported by Dimri et al. (2010) in sheep infested with Psoroptes ovis. Results of those studies confirm the hypothesis that a reduced content of analysed metals is related, at least partially, to their use in $\mathrm{Cu}, \mathrm{Zn}-\mathrm{SOD}$ synthesis. Chaudhuri et al. (2008) observed oxidative damage in dogs naturally infested with Babesia gibsoni, including a significant decrease in $\mathrm{Fe}, \mathrm{Zn}$ and $\mathrm{Cu}$ concentration in blood. According to those authors, a low content of the examined metals seems to play a role in the genesis of anaemia and oxidative stress. Based on the data provided in literature and our research, it can be assumed that these low contents of $\mathrm{Fe}, \mathrm{Cu}$ and $\mathrm{Zn}$ could be closely related (directly or indirectly) to the oxidative status of infested birds and could have resulted from using them to neutralize the excessive generation of reactive oxygen species (ROS) occurring during the red mite invasion.

Literature data report that one of the effects of red mites' preying is anaemia. Our studies demonstrated a significant decrease in Fe concentration in the liver with only slight variation of haematological indicators in the blood. Loss of blood stimulates the bone marrow to increased erythropoiesis to maintain an adequate number of red cells. In this case the demand for Fe intracellularly binding with ferritin and storing in the liver rises. Progressive diminution of Fe supplies in the liver and simultaneous proper or slight alterations in $\mathrm{RBC}, \mathrm{HGB}, \mathrm{MCH}$ and $\mathrm{MCV}$ are typical for so called latent Fe deficiency. 
This process can explain the lack of clinical symptoms of anaemia as well as significant changes in haematological indicators in hens infested with D. gallinae.

To summarize, based on the results obtained in our study, it was ascertained that longterm exposure of hens to Dermanyssus gallinae brought about a significant decrease in the concentration of $\mathrm{Fe}, \mathrm{Cu}$ and $\mathrm{Zn}$ in the liver. This can indicate anaemia, an inflammatory condition or lowered immunity caused by the presence of the parasite, as well as emergence of oxidative stress, since the analysed metals are transition metals fulfilling important roles in free radical processes. The obtained results may also suggest that only 3 weeks without parasites cause a significant increase in concentration of analysed metals in the liver.

\section{References}

Arkle S, Guy JH, Blackett SM, Sparagano O 2004: Variation in the population of Dermanyssus gallinae in a free range laying unit and effectiveness of chemicals control. Br Poultry Sci 41(Suppl.1): S45-S46

Camkerten I, Sahin T, Borazan A, Gokcen A, Erel O, Das A 2009: Evaluation of blood oxidant/antioxidant balance in dogs with sarcoptic mange. Vet Parasitol 161: 106-109

Chaudhuri S, Varshney JP, Patra RC 2008: Erythrocytic antioxidant defence, lipid peroxides level and blood iron, zinc and copper concentration in dogs naturally infected with Babesia gibsoni. Res Vet Sci 85: 120-124

Dimri U, Sharma MC, Yamdagni A, Ranjan R, Zama MMS 2010: Psoroptic mange infestation increases oxidative stress and decreases antioxidant status in sheep. Vet Parasitol 168: 318-322

Emerit J, Beaumont C, Trivin F 2001: Iron metabolism, free radicals, and oxidative injury. Biomed Pharmacother 55: 333-339

Evans P, Halliwell B 2001: Micronutrients: oxidant/antioxidant status. Br J Nutr 85 (Suppl. 2): S67-S74

Gaetke LM, Chow CK 2009: Copper toxicity, oxidative stress, and antioxidant nutrients. Toxicology 189: $147-163$

Georgieva NV, Koinarski V, Gadjeva V 2006: Antioxidant status during the course of Eimeria tenella infection in broiler chickens. Vet J 172: 488-492

Grewal A, Ahuja CS, Singha SPS, Chaudhary KC 2005: Status of lipid peroxidation, some antioxidant enzymes and erythrocyte fragility of crossbred cattle naturally infected with Theileria annulata. Vet Res Commun 29: 387-394

Guy JH, Khajavil M, Halele MM, Sparagano O 2004: Red mite (Dermanyssus gallinae) prevalence in laying units in Northern England. Br Poultry Sci 45 (Suppl. 1): S15-S16

Hirano T, Mukarami M, Fukada T, Nishida T, Yamasaki S, Suzuki T 2008: Roles of zinc and zinc signaling in immunity: zinc as an intracellular signaling molecule. Adv Immunol 97: 149-176

Kolodziejczyk L, Siemieniuk E, Skrzydlewska E 2006: Fasciola hepatica: effects on the antioxidative properties and lipid peroxidation of rat serum. Parasitol Res 113: 43-48

Kowalski A, Sokół R 2009: Influence of Dermanysus gallinae (poultry red mite) invasion on the plasma levels of corticosterone, catecholamines and proteins in layers hens. Pol J Vet Sci 12: 231-235

Kowalski A, Sokół R, Jedlińska-Krakowska M 2006: Influence of red mite Dermanyssus gallinae invasions on corticosterone and haematological levels and immunological indices in egg-laying hens. Medycyna Wet 62: $1188-1190$

Lieu PT, Haiskala M, Peterson PA, Yang Y 2001: The roles of iron in health and disease. Mol Asp Med 22: 1-87

Lykkesfeldt J, Svendsen O 2007: Oxidants and antioxidants in disease: oxidative stress in farm animals. Vet J 173: $502-511$

Sokół R, Barski D, Spodniewska A 2008: Activity of selected antioxidant enzymes in layer hens non-infected and infected with Dermanyssus gallinae. Bull Vet Inst Pulawy 52: 67-70

Stefanidou M, Maravelias C, Dona A, Spiliopoulou C 2006: Zinc: a multipurpose trace element. Arch Toxicol 80: $1-9$

Stehbens W 2003: Oxidative stress, toxic hepatitis, and antioxidants with particular emphasis on zinc. Exp Mol Pathol 75: 265-276

Szkoda J, Żmudzki J 1990: Determination of copper, iron, zinc in the biological material. Instruction for Institute of Veterinary Hygiene. National Veterinary Research Institute, Pulawy: 1-18

Zenner L, Bon G, Chauve C, Nemoz C, Lubac S 2009: Monitoring of Dermanyssus gallinae in free-range poultry farms. Exp Appl Acarol 48: 157-166 